\title{
Exposure Test of Oecophylla Smaragdina (Hymenoptera:Formicidae) for Controlling Damage from Prays Endocarpa (Lepidoptera:Yponomeutidae) on Pummelo (Citrus Maxima Merr.)
}

Andi Ridwan"1, Nurariaty Agus ${ }^{2}$, Melina ${ }^{3}$, Tamrin Abdullah ${ }^{4}$

${ }^{* 1}$ Doctoral Student, Hasanuddin University/Pest and Disease science,Makassar, South Sulawesi, Indonesia

${ }^{1}$ Department of Estate Crops Cultivation, Pangkep State Polytechnic of Agriculture, South Sulawesi, 90655, Indonesia

2Professor Department of Plant Pest and Disease, Hasanuddin University/Faculty of Agriculture, Makassar, South Sulawesi, Indonesia

${ }^{3,4}$ Lecturer Department of Plant Pest and Disease Hasanuddin University/Faculty of Agriculture, Makassar, South Sulawesi, Indonesia

\section{ABSTRACT}

Prays endocarpa Meyrick is a kind of pest that attacks pummelo (Citrus maxima Merr.) lowering the quality and the selling price of the fruits. Information about the use of ants as a pest predator has been widely found. This research aims to test the use of Oecophylla smaragdina ant to control attack from $P$. endocarpa on pummelo. Two treatments were carried out, namely treatment with exposure of $O$. smaragdina ants on fruiting stalks and without exposure of $O$. smaragdina ants. Exposure of $O$. smaragdina was carried out for three weeks since the fruits were still young, sized 10-15 millimeters. The level of attack and the number of fallen pummelo fruits were observed during six weeks of treatment. The observations showed that the average rate of damage of $P$. endocarpa was lower in treatment with exposure of $O$. smaragdina (17.24\%) compared to treatment without (81.25\%). Likewise, the results found on average of the number of fallen fruits were lower in treatment with exposure of $O$. smaragdina ants $(9.3 \%)$ compared to treatment without ant exposure (50.0\%). Mann Whitney test at the $0.05 \%$ level used for the two observations showed a significant difference between the two treatments. O. smaragdina ants are reliable as a controller for $P$. endocarpa damage on pummelo.

Keywords : Prays Endocarpa, Oecophylla Smaragdina, Pummelo, Controlling, Pests

\section{INTRODUCTION}

Pummelo (Citrus maxima Merr.) is a tropical fruit with high economic value and consumption level (Outlook, 2017). However, the attack of pest organisms $P$. endocarpa Meyrick can reduce the quality, quantity (production), and economic value of Pummelo.

A research done by Vang, et al. (2018) reveals that the pest $P$. endocarpa attacks newly formed fruits and can cause young fruits to fall. This results in a decrease in the quantity (production) of pummelo fruit. $P$. endocarpa attacks, besides reducing the quantity of production by the fall of young fruit that is attacked, also lowering the quality of citrus fruits because of the protuberances like "puru"(Indonesian) formed on the peel of Pummelo and are usually accompanied by cavities from the larvae (Ubaub and Ocampo, 2012). The condition causes Pamelo orange market to be limited to local consumers. As a result, the price is cheap. Pummelo cannot be widely marketed abroad because orange consumer countries require oranges to be healthy and smooth. Nurariaty and Melina (2009) 
state that $P$. endocarpa attack has reached $40 \%$ and caused the low quality of the citrus fruit in Pangkajene and Kepulauan Regency (Pangkep Regency).

Techniques for controlling plant pests that have been found and applied are inseparable from various weaknesses. In terms of its effectiveness, there are also environmental and safety issues for other organisms that are not targeted (Untung, 2015). Meanwhile, the use of chemicals for pest control has many negative impacts, both on the health of living things and the environment, in addition to the residues (De Bon et al. 2014). In general, efforts to develop control techniques for plant pests have been carried out. The important thing to note is that the control technique chosen is not only effective in controlling pests but can also be easily applied. Moreover, the material is easily obtained and it can be maximally used to prevent the plants from various unwanted risks. Therefore, throughout the world, researches continue to be intensified to develop alternative control strategies, including the use of biological agents (Van Lenteren 2000; Adandonon et al. 2009).

Several methods of controlling $P$. endocarpa pests have been recommended, as suggested by Gavarra (1990), which is by using insecticides. Furthermore, the treatment of cloaking small pamelo fruit is done using bags made of plastic or paper and natural enemies such as parasitoids as have been carried out by Nurariaty and Melina (2009).

Ants are one of the organisms known as biological agents, and their presence is easily found in various ecosystems. Ants have a cosmopolitan distribution because they spread widely in various habitats (Holldobler and Wilson 1990). The ability of ants to modify habitats, pressure resources, self-defense, and a cosmopolitan distribution causes ants to provide ecosystem services for the control of certain pests in various plants.

One type of ant that is often found and abundant in many types of plants is $O$. smaragdina. In Indonesia, these ants are known as rangrang ants. Information about the use of ants as predators of pests has been found. As in Australia, O. smaragdina is used to control Helopeltis pernicalis populations on cashew plants (Peng et al., 1999a; 1999b). In addition, in Solomon Islands, rangrang ants are used to control Amblypelta cocophaga and Brontispa longissima on coconut plants. In Malaysia, it is used as a controller for Heliotis theobromae in cocoa plants. In China, it is used to control Tessaratoma papillosa and Rhychoris humeralis in oranges. In Indonesia, it has been tested to control Cryptorrhynchus gravis on mango plants (Way and Khoo, 1992). Furthermore, in Tanzania, it has been reported regarding the effectiveness of $O$. smaragdina for controlling Helopeltis in cashew nuts (Olotu et al., 2013). In other commodities, Falahuddin (2015) also reveals the results of his study that arboreal ants, especially $O$. smaragdina, are predators that have the potential to control fire caterpillars on oil palm plants.

The role of $O$. smaragdina as a biological agent in the Pummelo ecosystem has not been studied and reported. This is the reason for the need to examine the use of $O$. smaragdina for controlling $P$. endocarpa on pummelo plants. The use of $O$. smaragdina ants for pest control of citrus plants is easier, cheaper, environmentally friendly, and available in local places.

\section{METHODS AND MATERIAL}

\section{A. Time and Location}

The study was conducted from September to November 2019 in Gellengnge Village, Ma'rang District, Pangkajene Kepulauan Regency, South Sulawesi Province, located about $50 \mathrm{~km}$ from Makassar City, the capital city of South Sulawesi 
Province. The location of the study is shown in Figure 1.

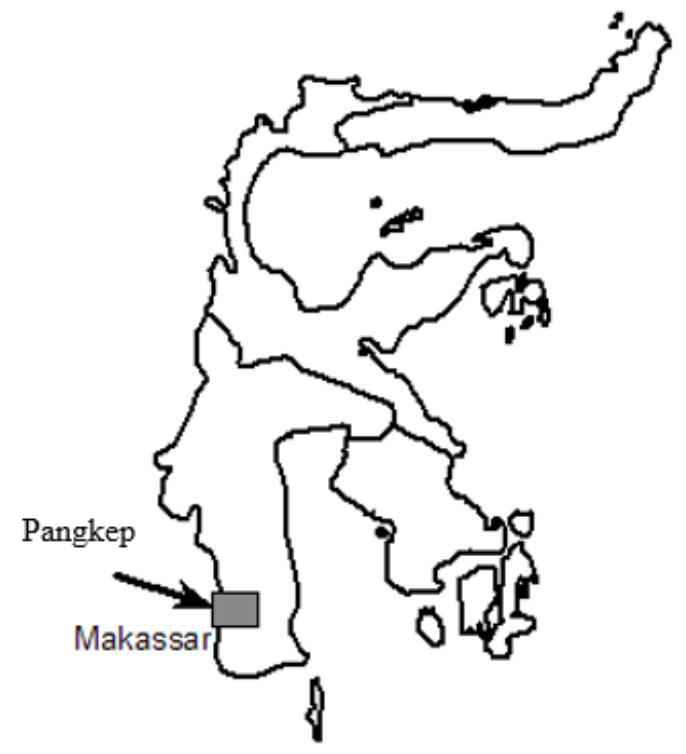

Figure 1. Sulawesi Island and the location of study area

\section{B. Preliminary research and research preparation}

Before conducting the main research, preliminary research and research preparation were carried out, in the form of:

1) Preliminary research examined chicken intestine bait, with field trial in the installation of fresh chicken intestine bait and cow fat on the branches of pummelo tree. The results showed that after installing the chicken intestine bait on the branches of the pamelo orange tree, it only took a few minutes to be immediately surrounded by $O$. smaragdina ants. This is in line with researches conducted by Offenberg, et al. (2013) and Peng and Christian (2007) who found that one of the most widely used bait to bring in ants was chicken intestine.

2) Preparation of research is in the form of demonstration plots in citrus orchards that have been in production.

\section{Research Treatment}

Based on the previous preliminary research, in this study, the bait used to attract $O$. smaragdina ants was fresh chicken intestine. Furthermore, the presence of
O. smaragdina ants was monitored and maintained on the Pummelo fruit stalk for three weeks. After six weeks, observations were made to see the attack of $P$. endocarpa on Pummelo. Observations were made at the age of six weeks because the symptoms of $P$. endocarpa attacks can already be seen clearly in that age.

Treatments carried out are treatment with exposure of $O$. smaragdina ants and without ant exposure. For ant exposure treatment, Pummelo trees contained $\mathrm{O}$. smaragdina ant colonies are selected. After then, stems on the trees containing two young Pummelo at the age of one week (10-15 mm in size) were selected. At a distance of $25 \mathrm{~cm}$ from the fruit, on the stalk, fresh intestine of chicken weighing 20 grams was bound with a plastic strap. The chicken intestine was used as bait to bring $O$. smaragdina ants to the stalk (Offenberg, J. at al. 2013). The number of fruit stems selected as treatment with exposure of $O$. smaragdina for each Pamelo orange tree is four stems, namely one stalk in each cardinal direction (North, East, South, and West). The fruit stems were selected on four Pummelo trees so 16 fruit stems would be sampled. Treatment conditions were monitored every three days. If the bait is reduced, more bait was added. This was done up to three weeks later. Treatment without $O$. smaragdina was carried out on another pummelo tree by applying glue (as a barrier) to avoid $O$. smaragdina ants to the pummelo fruit on the stem. Glue is placed as in ant exposure treatment. Observation of the level of attack due to $P$. endocarpa and deciduous fruit is done when the fruit is six weeks old.

Treatment:

1) Exposure of O. smaragdina:

Repetition 1: SP1U, SP1T, SP1S, SP1B

Repetition 2: SP2U, SP2T, SP2S, SP2B

Repetition 3: SP3U, SP3T, SP3S, SP3B

Repetition 4: SP4U, SP4T, SP4S, SP4B

2) Without exposure of $O$. smaragdina:

Repetition 1: TP1U, TP1T, TP1S, TP1B 
Repetition 2: TP2U, TP2T, TP2S, TP2B

Repetition 3: TP3U, TP3T, TP3S, TP3B

Repetition 4: TP4U, TP4T, TP4S, TP4B

\section{Data analysis}

The percentage of $P$. endocarpa symptomatic fruits in Pummelo was calculated using the formula:

$\%$ level of damage

$=\frac{\text { the number of fruits with symptoms }}{\text { the number of fruits left on the stalk }} \times 100$

The percentage of decapitated Pamelo oranges was calculated by the equation:

$\%$ fallen fruits

$=\frac{\text { the number of initial fruits - the number of left fruits }}{}$

$=\frac{\text { the number of initial fruits }}{x}$

$\times 100$

Data was analyzed using Mann Whitney.

\section{III.RESULTS AND DISCUSSION}

\section{A. The effect of exposure of $O$. smaragdina on the attack of $P$. endocarpa}

Exposure of $O$. smaragdina ant to Pummelo uses fresh chicken intestine bait. The presence of $O$. smaragdina ants is monitored and maintained on Pamelo orange stalk for three weeks. After six weeks, observations were done to see the severity of the attack of $P$. endocarpa on Pummelo. Observations were made at the age of six weeks because the symptoms of $P$. endocarpa attacks can already be seen clearly at that age. The results of observations of the rates of $P$. endocarpa attack are shown in Table 1.

TABLE 1. THE EFFECT OF O. SMARAGDINA ON THE LEVEL OF P. ENDOCARPA ATTACK ON PUMMELO

\begin{tabular}{lccc}
\hline Treatment & $\begin{array}{c}\text { Mean \% of the } \\
\text { level of } \\
\text { Damage }(\mathrm{x} \pm \mathrm{sd})\end{array}$ & $\begin{array}{c}\text { Rank } \\
\text { Sum }\end{array}$ & $\begin{array}{c}\text { P value* } \\
\text { (Asym.Sig2) }\end{array}$ \\
\hline $\begin{array}{l}\text { Without } \\
\begin{array}{l}\text {. } \\
\text { smaragdina }\end{array}\end{array}$ & $81.25 \pm 0.83$ & 309.00 & 0.049 \\
$\begin{array}{l}\text { With } O \text {. } \\
\text { smaragdina }\end{array}$ & $17.24 \pm 0.70$ & 219.00 & \\
\hline
\end{tabular}

${ }^{*} \mathrm{P}$ value $<0.05$ shows significant differences based on Mann-Whitney test.

The average rate of $P$. endocarpa attack as shown in Table 1 shows that in fruit stalks exposed to $O$. smaragdina ants for three weeks, the average damage rate of $P$. endocarpa is $17.24 \%$. Meanwhile, on fruit stalks not exposed to $O$. smaragdina ants, the attack rate is $81.25 \%$. The exposure of $O$. smaragdina to pummelo can reduce the rate of $P$. endocarpa attack as many as $64 \%$. The results of Mann Whitney test show a significant difference between the two treatments $\mathrm{P}<0.05$.

The attack rate of $P$. endocarpa appeared to be greater in fruits without $O$. smaragdina exposure compared to fruits that were treated with $O$. smaragdina exposure. This shows that the presence of $O$. smaragdina on fruit stalks can prevent and supervise citrus fruits from being attacked by $P$. endocarpa laying their eggs on Pamelo. The lack of $P$. endocarpa chance to reach citrus fruits as a medium for laying eggs has implications for the reduced damage caused by $P$. endocarpa in pummelo. It can be concluded that $O$. smaragdina can prevent and reduce the possibility of $P$. endocarpa reaching the Pummelo.

The ability of ants as biological agent organisms that can reduce the level of $P$. endocarpa attacks is inseparable from the characteristics of ants that have a cosmopolitan distribution spread widely in various habitats (Holldobler and Wilson 1990). The success of ants is associated with social behavior such as the division of labor and communication between individuals (Holldobler and Wilson 1990). The success of ants in the environment is inseparable from the ability of ants to modify habitat, resource pressure, and self-defense (Andersen et al., 2002). Furthermore, according to Holldobler and Wilson (1990), ants naturally can have a variety of relationships with other organisms, namely commensalism, parasitism, 
and mutualism. The collective impact of ants on the biology of other organisms is reflected in thousands of plant and animal species that have special adaptations related to ants through symbiotic relationships. Ants are found in both ecosystems that have been managed by humans (agro-ecosystems) and native ecosystems (Peng et al., 1999). The ability of ants to modify habitats, pressure resources, and self-defense, and to have a cosmopolitan distribution, causes them to provide ecosystem services for controlling certain pests in various plants.

The findings of this study are in line with the findings of Olotu et al. (2013), Peng et al. (1999a), and Way and Khoo (1992) who use $O$. smaragdina as a predator to control various types of pests that attack horticultural and plantation crops. $O$. smaragdina can control most of the pests on mango and cashew plants, as well as protect coconut and cocoa plants from attacks by ladybugs, increasing the quality and quantity of the crop (Van Male and Cuc, 2004).

\section{B. The effects of exposure of $O$. smaragdina ants on the number of fallen fruits}

The attack rate of $P$. endocarpa on Pamelo citrus fruit is directly proportional to the number of fallen fruits. The number of fallen fruit in each treatment is shown in table 2.

Table II. The effect of $O$. smaragdina on the number of fallen fruits on Pummelo plants

\begin{tabular}{lccc}
\hline Treatment & $\begin{array}{c}\text { Mean \% } \\
\text { fallen fruits } \\
(\mathrm{x} \pm \mathrm{sd})\end{array}$ & $\begin{array}{c}\text { Rank } \\
\text { Sum }\end{array}$ & $\begin{array}{c}\text { P value* } \\
\text { (Asym.Sig2) }\end{array}$ \\
\hline $\begin{array}{l}\text { Without } \\
\text { O. }\end{array}$ & $50.0 \pm 0.73$ & 342.00 & 0.001 \\
smaragdina & & & \\
With O. & $9.3 \pm 0.54$ & 186.00 & \\
smaragdina & & & \\
\hline
\end{tabular}

${ }^{*} \mathrm{P}$ value $<0.05$ shows significant difference based on Mann-Whitney test
Table 2 shows that the percentage of fallen fruits in treatment without $O$. smaragdina is $50 \%$, while the percentage of fallen fruits in the treatment with $O$. samaragdina is $9.3 \%$. The exposure of $O$. smaragdina to pummelo can reduce the number of fallen fruits due to $P$. endocarpa attack, and the reduction reaches $40.7 \%$. Based on the results of Mann Whitney test, there is a significant difference between treatments $\mathrm{P}$ $<0.05$ (Table 2).

The percentage of fallen fruits in fruit stalks which were not treated with exposure of $O$. smaragdina is greater compared to fruit stalks which were treated with $O$. smaragdina. This implies that the presence of $O$. smaragdina can reduce the number of pamelo fruits that fall from the stem. The reduced number of fallen fruit on stems that receive $O$. smaragdina treatment is related to the reduced $P$. endocarpa attacks (Table 1). This is in accordance with what is said by Vang, L.V. et al. (2018) that the attack of P. endocarpa on Pummelo can cause young fruits to fall. Thus, it can be said that the attack of $P$. endocarpa on Pummelo can cause pummelo to fall. The higher the attack of $P$. endocarpa, the higher the fruit that fall will be.

\section{Implication on the development of agriculture}

The results of the research show that exposure of $O$. smaragdina to pummelo can reduce the level of $P$. endocarpa attack that impact the reduction of fallen fruits due to $P$. endocarpa attack. These results provide important significance for the development of an environment-friendly agricultural sector. Pest control on citrus plants using $O$. smaragdina ants can be recommended as an effective and efficient alternative to control $P$. endocarpa attacks. The use of $O$. smaragdina as a biological agent is easier, cheaper, environment-friendly, and available locally. 


\section{IV.CONCLUSION}

The results show that the exposure of $O$. smaragdina to pummelo can reduce the level of $P$. endocarpa damage for $64.01 \%$, resulting in the reduction of fallen fruits due to $P$. endocarpa attack for $40.7 \%$.

\section{REFERENCES}

[1] Andersen, A.N., Hoffmann, B.D., Müller, W.J. and Griffiths, A.D. 2002. Using ants as bioindicators in land management: simplifying assessment of ant community responses. Journal of Application Ecology (39): 8-17.

[2] Adandonon, A., Vayssières, J-F., Sinzogan, A. and Van Mele P. 2009. Density of pheromone sources of the weaver ant Oecophylla longinoda affects oviposition behaviour and damage by mango fruit flies (Diptera: Tephritidae). International Journal of Pest Management 55(4): 285-292.

[3] Centre for Agricultural Data and Information System, 2017. Outlook of Agricultural Commodities of Sub Horticultural Sector, Orange. Ministry of Agriculture, Jakarta.

[4] De Bon, H., Huat, J., Parrot, L., Sinzogan, A., Martin, T., Malézieux, E. and Vayssières, J-F., 2014. Pesticide risks from fruit and vegetable pest management by small farmers in subSaharan Africa. A review. Agronomy for Sustainable Development, DOI 10.1007/s13593014-0216-7

[5] Falahuddin, I. 2015. Arboreal ant diversity (Hymenoptera: Formicidae) and its potency as a cup moth control (Lepidoptera: Limacodidae) on oil palm plants. Dissertation. Andalas University.

[6] Gavarra, M., Costales, D., and Arano, B. 1990. The Identity biologi, ekology and control of citrus rind borer, Prays endolemmai in the Philiphines. Unpublished paper presented during the $60^{\text {th }}$ Anniversary of the Bureau of Plant industry. San Andres, Malate, Manila. 26 p.

[7] Hölldobler, B. and Wilson, E. O. 1990. The Ants. Cambridge, Massachusetts: Harvard Univ. Press.

[8] Mele, P.V. and Cuc NTT. 2004. Ants as friends: improving your tree crops with weaver ants. Africa Rice Center, Cotonou and CABI, Egham.

[9] Nurariaty, A. and Melina. 2009. The utilization of eggs parasitoid and cloaking of fruits to control pests of Prays endocarpa in the Pomelo crop planting (Citrus grandis L.) in the Pangkep Regency. Abstract. Repository Hasanuddin University

[10] Offenberg, Joachim, Cuc, T.T and Wiwatwitaya, D. 2013. "The Effectiveness of Weaver Ant (Oecophylla Smaragdina) Biocontrol in Southeast Asian Citrus and Mango.” 5:139-49. Retrieved May 4, 2017

[11] Olotu, M.I., Plessis, D., Seguni, Z.S., Maniania, N.K. 2013. Efficacy of the African weaver ant Oecophylla longinoda (Hymenoptera: Formicidae) in the control of Helopeltis spp. (Hemiptera: Miridae) and Pseudotheraptus wayi (Hemiptera: Coreidae) in cashew crop in Tanzania. International Centre of Insect Physiology and Ecology icipe, Nairobi, Kenya. Pest Manag Sci. 2013 Aug;69(8):911-8. doi: 10.1002/ps.3451

[12] Peng, R.K., Christian, K. and Gibb, K. 1999a. The effect of colony isolation of predacious ant, Oecophylla smaradigna (Hymenoptera; Formicidae), on protection of cashew plantations from insects pest. International Journal of Pest Management, 45. 189-194.

[13] Peng, R.K., Christian, K., and Gibb, K. 1999 b. The effect of levels of green ant, Oecophylla smaragdina (F), colonization on cashew yield in Northern Australia Biological Control in the Tropics. Proceedings of the Symposium on 
Biological Control in The Tropics, Serdang, Malaysia. P. 24-28

[14] Peng, R.K. and Christian, K., 2007. The effect of the weaver ant, oecophylla smaragdina (Hymenoptera: Formicidae) on the mango seed weevil, Sternochetus mangifera (Coleoptera: Curculionidae) in mango orchads in the northern teritory of Australla. International Journal of Pest Management 53:1.15-

[15] Ubaub and Ocampo. 2012. Field Biology Setal Map and Adult Genitalia of the Citrus Rind Borer Prays endolemma Diakonoff (Lepidoptera: Yponomeutidae) on Pummelo Citrus maxima (Burn) Merr. Rutaceae in Region XI Philippines. Phillipp Ent 26(1): 65-92 University of the Philippines Los Barlos College

[16] Untung, K. 2015. Introduction to Integrated Pest Management - $2^{\text {nd }}$ Edition. Sixth Printing. Publisher: UGM Press. 348 hal.

[17] Van Lenteren, J.C. 2000. Measures of success in biological control of arthropods by augmentation of natural enemies. In Measures of Success in Biological Control (Wratten S. and Gurr G, eds.). Kluwer Academic Publishers, Dordrecht, The Netherlands, 77-103.

[18] Vang, L.V., Son, P.K and Khanh, C.N.Q. 2018. Monitoring population dynamics of the citrus pock caterpillar (Prays endocarpa) by sex pheromone traps in the Mekong Delta of Vietnam. Can Tho University Journal of Science. Vol. 54, No. 2 (2018): 35-39. DOI: 10.22144/ctu.jen.2018.005

[19] Way, M.J. and Khoo, K.C. 1992. Role of ants in pest management. Annual Review of Entomology 37: 479 - 503.

\section{Cite this article as :}

Andi Ridwan, Nurariaty Agus, Melina, Tamrin Abdullah, "Exposure Test of Oecophylla Smaragdina (Hymenoptera:Formicidae) for Controlling Damage from Prays Endocarpa (Lepidoptera:Yponomeutidae) on Pummelo (Citrus Maxima Merr.)", International Journal of Scientific Research in Science and Technology (IJSRST), Online ISSN : 2395-602X, Print ISSN : 2395-6011, Volume 6 Issue 6, pp. 289-295, November-December 2019. Available at doi : https://doi.org/10.32628/IJSRST196663 Journal URL : http://ijsrst.com/IJSRST196663 